\title{
EL IMAGINADO "PATRIMONIO INMATERIAL» ¿UN ACERCAMIENTO A LA VERDAD O UNA FALSEDAD ENGAÑOSA?
}

\author{
THE IMAGINED «INTANGIBLE HERITAGE» \\ APPROACH TO MISLEADING TRUTH OR FALSE?
}

\section{JESÚS GUANCHE PÉREZ}

Licenciado en Historia del Arte, Universidad de La Habana, 1976. Doctor en Ciencias Históricas, Instituto de Etnografía «Mixlujo Maklai» de la Academia de Ciencias de la URSSS, 1983. Profesor Titular de la Universidad de La Habana desde 1990. Investigador Titular de la Academia de Ciencias de Cuba desde 1984. Investigador Titular del Centro de Investigación y Desarrollo de la Música Cubana (CIDMUC) del Instituto Cubano de la Música, Ministerio de Cultura, 1987-1997. Investigador Titular de la Fundación Fernando Ortiz. Profesor Titular Adjunto de la Facultad de Artes y Letras, y de Filosofía e Historia de la Universidad de La Habana y del Instituto Superior de Arte.

\section{RESUMEN:}

Este trabajo discute y somete a crítica la cualidad absurda del pseudoconcepto identificado por la UNESCO como «patrimonio cultural inmaterial» y su versión simple de «patrimonio inmaterial», así como la versión limitadamente sensualista de «patrimonio cultural intangible». Al mismo tiempo, valora y contrapone la significación conceptual del patrimonio cultural vivo como cualidad interactiva y dinámica de procesos culturales valorables desde el punto de vista patrimonial.

\section{PALABRAS CLAVE:}

Patrimonio cultural vivo, patrimonio cultural inmaterial, patrimonio inmaterial, falsedad/verdad, cuerpo/alma, materia/espíritu

\begin{abstract}
:
This article discusses and looks over qualifications as "Intangible Cultural Heritage" and/or "Intangible Heritage" by UNES$\mathrm{CO}$. At the same time, this article evaluates and contrasts the significance of the living cultural heritage as a dynamic and interactive quality of valuable cultural processes rising from heritage.
\end{abstract}

\section{KEYWORDS:}

Living cultural heritage, intangible cultural heritage, intangible heritage, false / true, body / soul, matter / spirit 


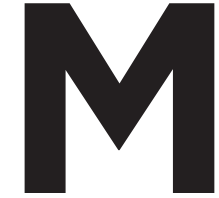

uchas personas honestas y diversos gobiernos, tras efectuarse la aprobación internacional de la CONVENCIÓN PARA LA SALVAGUARDIA DEL PATRIMONIO CULTURAL INMATERIAL, por la UNESCO, en octubre de 2003, han seguido repitiendo de buena fe tanto la idea sobre la protección del así denominado «patrimonio cultural inmaterial», como la acepción simplificada de «patrimonio inmaterial», sin detenerse a reflexionar sobre las múltiples implicaciones que esto puede tener en los ámbitos del conocimiento científico, su influencia en una opinión pública adecuadamente informada y en la aplicación consecuente de políticas culturales que, lejos de interpretar y asumir los problemas humanos en su complejidad, tienda nuevamente a separar la realidad en compartimentos estancos como reflejo de la imposición de criterios clasificadores y limitadores de las ideas a los hechos de la vida cotidiana.

Esta idea del denominado «patrimonio cultural inmaterial» es sencillamente un absurdo si lo relacionamos con lo que pretende definir la propia Convención; es decir:

“...los usos, representaciones, expresiones, conocimientos y técnicas -junto con los instrumentos, objetos, artefactos y espacios culturales que les son inherentes- que las comunidades, los grupos y en algunos casos los individuos reconozcan como parte integrante de su patrimonio cultural. Este patrimonio cultural inmaterial, que se transmite de generación en generación, es recreado constantemente por las comunidades y grupos en función de su entorno, su interacción con la naturaleza y su historia, infundiéndoles un sentimiento de identidad y continuidad y contribuyendo así a promover el respeto de la diversidad cultural y la creatividad humana. A los efectos de la presente Convención, se tendrá en cuenta únicamente el patrimonio cultural inmaterial que sea compatible con los instrumentos internacionales de derechos humanos existentes y con los imperativos de respeto mutuo entre comunidades, grupos e individuos y de desarrollo sostenible..." (Convención para la Salvaguardia del Patrimonio Cultural Inmaterial, 2000)

Todo ello se refiere a manifestaciones creadas, portadas y transmitidas por seres humanos vivos o que lo transmitieron durante su ciclo vital. Nada más ajeno a una supuesta «inmaterialidad» que la propia cultura.

Si damos por sentado que la concepción de denominar «patrimonio cultural inmaterial» a las expresiones de la cultura no identificadas con objetos ya definidos anteriormente como «patrimonio cultural material», el principio de identificación o punto de partida ha sido falso, erróneo; pues se basó en una lógica maniquea, vulgar; limitada en su propia definición a la exclusiva oposición binaria de antónimos: se partió del principio simple de que si hay algo negro, lo opuesto tiene que ser blanco; si hay algo grande, lo opuesto tiene que ser pequeño; si hay algo material lo opuesto debe ser «inmaterial», y así sucesivamente, sin evaluar las implicaciones abarcadoras del concepto filosófico de materia como manera de identificar a la propia realidad en su complejidad diversa y cambiante.

De este modo se recurrió a un obsoleto léxico jurídico ${ }^{1}$ (en su versión francohablante, la de «patrimonio inmaterial» o la de su versión anglohablante y limitadamente sensualista, la de «patrimonio intangible» ${ }^{2}$ ), relacionado con el derecho privado para tratar de diferenciarlo del también denominado patrimonio material, aunque relacionado nada menos que con los bienes culturales y con los derechos colectivos.

Recordemos que en el orden lógico, para tratar de alcanzar el pensamiento correcto, la falsedad es un concepto válido opuesto a la verdad. La falsedad se caracteriza por el «conocimiento incierto cuya correspondencia con los fenómenos y objetos del mundo circundante no puede ser confirmado por la práctica». (Getmanova et al., 1991. pp.102). El propio Aristóteles caracterizó la falsedad como «quien piensa lo contrario a como son las cosas» (Getmanova et al, 1991), y posteriormente Marx (citado por Getmanova et al, 1991) señaló que «El pensamiento erróneo fabrica indefectible e involuntariamente hechos erróneos y por tanto produce tergiversación y falsedad». (Getmanova et al, 1991). Sin embargo, la falsedad se puede presentar de forma impremeditada (paralogismo) y premeditada (sofisma). En el caso que veremos sobre el supuesto «patrimonio inmaterial», todo el análisis indica que nos encontramos en presencia de un sofisma que parte de un principio lógico falso.

Ante esta situación, que podría resultar engañosa, cabe preguntar: ¿Qué se encuentra en el substrato gnoseológico de toda esta supuesta dicotomía entre lo material y lo «inmate-rial» asociado al tema del patrimonio cultural? ¿Esta separación es realmente el resultado de un razonamiento científico actual o de la acumulación histórica de diferentes cosmovisiones que separan idealmente al cuerpo del alma, a la materia de la conciencia? ¿Es esto realmente separable o es solo fruto de la imaginación humana?

Aunque toda definición tiene valor operacional e histórico y esta puede cambiar o resemantizarse de acuerdo con el propio desarrollo de los conocimientos, partimos de la siguiente definición amplia de materia; es decir, mucho más allá de su común y limitada acepción física, corpórea o mundana. Como bien refiere el filósofo Gustavo Bueno:

Obsoleto en relación con el avance actual del conocimiento científico, especialmente de la isica, biologia, metodología, filosofía, antropología, entre otros campos disciplinares.

Esta denominación reduccionista limita también este tipo de patrimonio solo a la percepción mediante el tacto y evidencia su insuficiencia. 
ARTE \& DISEÑO, ISSN: 1692-8555, Vol. 12 Núm. 1, Enero - Junio 2014 JESÚS GUANCHE PÉREZ

"El término materia designará inicialmente a la materia determinada, es decir, a todo tipo de entidad que, dotada de algún tipo de unidad, consta necesariamente de multiplicidades de partes variables (cuantitativas o cualitativas) que, sin embargo, se codeterminan reciprocamente (causalmente, estructuralmente). La materia determinada comprende diversos géneros de materialidad: un primer género, que engloba a las materialidades dadas en el espacio y en el tiempo (a las materialidades fisicas); un segundo género que comprenden a las materialidades dadas antes en una dimensión temporal que espacial (son las materialidades de orden subjetivo) y un tercer género de materialidades, en el que se incluyen los sistemas ideales de indole matemática, lógica y que propiamente no se recluyen en un lugar o tiempo propios. (Bueno, 1990. pp 49 - 50).

Como el ámbito de complejidad que abarca la materia rebasa autor añade seguidamente:

En una segunda fase, el término materia, al desarrollarse dialécticamente mediante la segregación sucesiva de toda determinación, puede llegar a alcanzar dos nuevas acepciones, que desbordan el horizonte de la materia determinada: la acepción de la materia cósmica (como negación de la idea filosófica de espiritu, en tanto el espíritu se redefine filosóficamente por medio del concepto de las formas separadas de toda materia) y la acepción de la materia indeterminada o materia prima en sentido absoluto, como materialidad que desborda todo contexto categorial y se constituye como materialidad trascendental.(Bueno, 1990. pp. 50).

Explicado de otro modo a la luz de la valoración y actualidad sobre ¿Qué es la «materia»?, Eduardo Robredo Zugasti sintetiza:

La doctrina de los tres géneros de materialidad [determinada] no es empírica ni a priori, sino más bien empirico-trascendental.

M1, M2 y M3 son partes del mundo entretejidas distributivamente (diaméricamente) lo que implica entenderlas como géneros comunicables entre sí, sin que esto implique, según la tesis symplokética, la conexividad total de todas las partes (esto es, no todo está relacionado con todo).

M1: Son las entidades del mundo externo, el conjunto de las realidades fenomenológicas exteriores a nuestra conciencia y que, de modo general, estudia la física. [... M1 no implica corporeísmo, puesto que algunas de las entidades fisicas pueden a su vez carecer de «cuerpo físico» (los fotones o los neutrinos, por ejemplo).

M2: Son el conjunto de procesos y entidades relacionadas con el interior, con el mundo de la interioridad psicológica; unos procesos que no se constituyen autorreflexivamente, sino siempre en codeterminación con los condicionantes exteriores (la conciencia es fundamentalmente social, y no tanto individual). M2, por consiguiente, no implica subjetivismo, ni espiritualismo.

M3: Son los objetos abstractos, matemáticos e ideales. Ahora bien, M3 tampoco es una idea metafisica ni espiritualista, pese a no darse propiamente ni externa ni exteriormente, y esto porque los contenidos abstractos no pueden considerarse «exentos» (eternamente existentes en un presunto «cielo platónico»), sino únicamente como resultado de la intersección o la mediación de la conciencia filosófica entre los planos de M1 y M2. (Zugasti, 2002).

Son precisamente los géneros M2 y M3 los que han sido identificados como imaginariamente «inmaterial», por sus cualidades complejas de existencia en el ámbito psicológico y en el desa-rrollo del pensamiento abstracto.

Todo lo anterior resulta paradójico. En un contexto internacional de profundos y acelerados avances del conocimiento, con campos del saber de tanta significación para el desarrollo humano y con inmensas perspectivas como la nanotecnología ${ }^{3}$ y el empleo de las células madres ${ }^{4}$, por ejemplo, parece una propuesta poco feliz y anacrónica colocar términos inoperantes para proteger nada menos que el patrimonio cultural de la propia humanidad, aunque pueda estar cargado de buenas intenciones.

\section{LA IDEA DE LO «INMATERIAL»Y DE LA MATERIA EN EL SUBSTRATO FILOSÓFICO Y RELIGIOSO}

Es importante recordar que en diversas religiones, cosmovisiones y filosofías, la idea de alma (ánima) se identifica con el elemento supuestamente «inmaterial», en oposición al cuerpo como elemento material en su primaria evidencia física. $\mathrm{El}$ alma es concebida como un principio interno, vital y espiritual, se relaciona con la fuente de todas las funciones fisiológicas, y particularmente de las actividades mentales, como si no fuera parte de la materia viviente. Prácticamente en muchas cultu-

3

Los materiales fabricados con esta tecnología podrían proporcionar estructuras con una sistencia sin precedentes y computadoras extraordinariamente compactas y potentes. La ducir a métodos revolucionarios de fabricación átomo por átomo

Cada célula madre (conocida en inglés como stem cell) es el tipo de célula no diferenciada apaz de experimentar divisiones ilimitadas y producir células hijas que pueden dar origen los distintos tipos de ćlulas presentes en el organismo. Véase Encarta 2007. 
ras conocidas se reitera la idea, (en tanto saber mundano), acerca de la existencia de algún tipo de alma capaz de existir independientemente del cuerpo. En muchas culturas contemporáneas basadas en la tradición oral se narra que los seres humanos tienen o pueden tener varias almas localizadas en diferentes partes del cuerpo, cada una con distintas funciones. La enfermedad está vinculada frecuentemente con la pérdida del alma; la muerte se asocia con el escape definitivo del alma. Esto puede ocurrir, por ejemplo, cuando las brujas roban o chupan el alma de los niños a través del ombligo o los espíritus del mal se apropian de una víctima.

En la India, por ejemplo, la creencia en el alma ha sido fundamental en varios sistemas filosóficos y religiosos. En los inicios del hinduismo el alma (atmán) estaba identificada con el principio que controla todas las actividades y definía la identidad del individuo y su conciencia. Conocidas obras filosóficas hindúes, como los Upanisad ${ }^{5}$, asocian el atmán con lo divino (Brahman) y le otorgan una dimensión eterna. A partir de esta idea, el alma humana es sometida a un ciclo de sucesivas reencarnaciones hasta que alcanza la purificación y el conocimiento se funde de nuevo con la realidad.

Sin embargo, el budismo ha sido único en la historia de las religiones porque afirma que el alma individual es una ilusión producida por diversas influencias psicológicas y fisiológicas. No tiene concepción de un alma o ser que pueda sobrevivir a la muerte. El punto de vista budista sobre la reencarnación no es otro que el de una cadena de consecuencias mediatizadas por cualquier identidad continuada, aunque en la creencia popular esta sutileza suele perderse y los creyentes consideran a los muertos como almas transmigratorias.

En China, por ejemplo, las ideas desarrolladas durante la dinastía Song (960-1279) dieron origen a un nuevo sistema de pensamiento confuciano basado en una mezcla de elementos budistas y taoístas; la nueva escuela fue conocida como neoconfucianismo. Los pensadores que asumieron este sistema intelectual conocían bien las otras dos filosofías. Destacados profesores de ética dedicaron su interés a las teorías sobre el cosmos y el origen del ser humano. El neoconfucianismo se ramificó en dos escuelas.

El exponente más conocido de una de estas escuelas fue Zhu $X i$, quien estableció una nueva base filosófica para las enseñanzas del confucianismo. Según él, todos los objetos en la naturaleza están compuestos por dos fuerzas inherentes: $l i$,

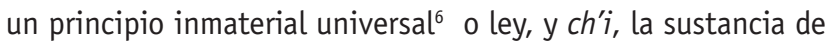

5 tas escrituras hindúes místicas y esotéricas fueron agrupadas en las Aranyakas, que forman parte de los Veda. Los conceptos filosóficos contenidos en ellos sirvieron como bas a uno de los seis sistemas ortodoxos de la filosofía hindú conocido como vedanta. Existen
150 Upanisad (108 según el número aceptado de acuerdo con la tradición), la mayoría de las unos 150 upanisad (108 segun el numero aceptado de acuerdo con la tradición), la mayoría de las

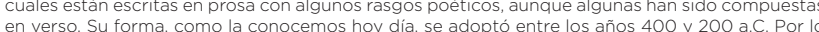
en verso. Su forma, como la conocemos hoy dia, se adopto entre los años 400 y 200 a.C. Por lo textos fueron compuestos en el siglo VI a.C.).

6 la que están hechas todas las cosas materiales. Mientras ch'i puede cambiar y disolverse, li, la ley subyacente y nutrida de miríadas de cosas, permanece constante e indestructible.

La concepción anterior identifica el li en la humanidad con la naturaleza humana, que es en esencia la misma para todo el mundo. El fenómeno de las diferencias particulares puede atribuirse a la variedad de proporción y densidad del ch'i hallado entre los individuos. Así, aquellos que reciben un $c h^{\prime} i$ que es turbio encontrarán su naturaleza original oscurecida y deberán limpiar su naturaleza para restaurar su pureza. La pureza puede alcanzarse ampliando el conocimiento propio del li en cada objeto concreto. Cuando, después de mucho esfuerzo, el li universal o ley natural inherente en todo objeto animado e inanimado, se adquiere la condición de sabio. Aquí la idea de lo «inmaterial» se universaliza y permanece inmutable en esta concepción.

Opuesta a la escuela del li (ley inmaterial inmutable) está la del neoconfucianismo hsin (mente). Su máximo exponente fue Wang Yang-ming, quien enseñó la unidad del conocimiento y de la práctica. Su afirmación principal fue que «aparte de la mente, ni ley ni objeto» existen. En la mente, afirmaba, se encuentran personificadas todas las leyes de la naturaleza, y nada existe sin la mente. El esfuerzo supremo debería ser desarrollar «el conocimiento intuitivo» de la mente, no a través del estudio o la investigación de la ley natural, sino mediante el razonamiento intenso y la meditación en calma. De este modo, la realidad es una ilusión y solo existe lo que cada individuo es capaz de representar en su mente. Este es otro ejemplo de idealismo subjetivo que en gran medida se complementa con el anterior por una firme base religiosa.

Durante la dinastía Qing (1644-1912) hubo una fuerte reacción contra ambas escuelas de pensamiento neoconfucianas, $l i$ y hisin. Los eruditos Qing proponían una vuelta al inicial y auténtico confucianismo del periodo de la dinastía Han, cuando todavía no había sido influido por las ideas taoístas y budistas. Desarrollaron una crítica de los textos clásicos confucianos basada en la metodología científica, utilizando la filología, la historia y la arqueología para reforzar su erudición. Además, eruditos como Tai Chen introdujeron un punto de vista empirista en el conjunto de la filosofía confuciana. Por tal motivo, no es nada raro que el substrato histórico de estas ideas que distinguen el cuerpo material y el alma ideada como «inmaterial» aún prevalezca en parte del pensamiento asiático.

En Europa medieval el conocido filósofo y teólogo italiano Santo Tomás de Aquino (1225-1274) se destacó por la defensa de la religión católica apostólica y romana sobre el principio espiritual humano con la afirmación averroísta de la autonomía del conocimiento derivado de los sentidos. Insistía en que las verdades de la fe y las propias de la experiencia sensible, así como las presentaba Aristóteles, son compatibles y complementarias. Algunas verdades, como el misterio de la Encarnación, podían ser conocidas solo a través de la revelación, y otras, como la composición de las cosas materiales, sólo a 
través de la experiencia; otras, como la existencia de Dios, son conocidas a través de ambas por igual.

Así, la fe guía al hombre hacia su fin último, Dios; supera a la razón, pero no la anula. Todo conocimiento, afirmaba, tiene su origen en la sensación, pero los datos de la experien-cia sensible pueden hacerse inteligibles solo por la acción del intelecto, que eleva el pensamiento hacia la aprehensión de tales realidades inmateriales ${ }^{7}$ como el alma humana, los ángeles y Dios. Para lograr la comprensión de las verdades más elevadas, aquellas con las que está relacionada la religión, es necesaria la ayuda de la revelación. En su filosofía de la política, a pesar de reconocer el valor positivo de la sociedad humana, justificó la perfecta racionalidad de la subordinación del Estado a la Iglesia.

Como ningún otro teólogo o filósofo, Santo Tomás organizó el conocimiento de su tiempo y lo puso al servicio de su fe. En su esfuerzo para reconciliar fe con intelecto creó una síntesis filosófica de las obras y enseñanzas de Aristóteles y otros sabios clásicos: de san Agustín y otros padres de la Iglesia, de judíos como Maimónides y Solomon ben Yehuda ibn Gabirol, y de sus predecesores en la tradición escolástica. Santo Tomás consiguió integrar en un sistema ordenado el pensamiento de estos autores con las enseñanzas de la Biblia y la doctrina católica. También influyó sobremanera en el pensamiento occidental en la separación de las ideas de cuerpo y alma.

Otro proceso histórico en el campo de las ideas es el que se desarrolla sobre la materia y que no da cabida a la noción de «lo inmaterial».

La propuesta de oponer una terminología científica a otra que no lo es se debe precisamente porque el pensamiento científico es sistemático y crítico no solo con la realidad sino consigo mismo. Por ello el referido trabajo de Robredo valida el significado de la ciencia del siguiente modo:

La consecuencia de esta distinción [sobre el acercamiento dialéctico a la verdad] es la concepción de la ciencia como un instrumento abierto hacia la comprensión del mundo, dado que está sometida a una revisión y perfeccionamiento permanentes. La ciencia, por consiguiente, no «cierra» el mundo, sino que nos lo abre, en consonancia con el axioma materialista de la infinitud y eternidad del universo. (Zugasti, 2002).

La supuesta oposición sobre materia/inmateria o antimateria, según Bueno (1990, p. 9), ha estado muy marcada por el efecto de «ciertas fórmulas aristotélicas o neoplatónicas asimiladas por el cristianismo y convertidas en "sentido común" y es

también el caso de ciertas fórmulas procedentes de los físicos materialistas del siglo [XIX], ampliamente divulgadas a través de una intensa labor escolar», que la circunscribe a su estricta acepción corpórea, de estirpe mundana o vulgar.

Frente a la aceptación acrítica de la percepción popular o mundana cual «legisladora de la razón» - al decir de Kant-, si se interpreta desde el legado metodológico aportado por la dialéctica, tal como enfatiza Bueno:

"Legislación no es magisterio o canon de verdad filosófica, capaz de garantizar la pureza de los contenidos, sino contexto determinante de los propios contenidos con los cuales la razón filosófica trabaja, muchas veces a contracorriente de la filosofia mundana dominante, «desobedeciendo», por así decir, a sus leyes, aunque siempre contando con ellas. En este punto parece pertinente subrayar que ha sido la tradición marxista una de las que más ha insistido, sin perjuicio de su dogmatismo ocasional, en la contraposición entre un materialismo vulgar (que incluye múltiples usos del término «materia» propios del lenguaje mundano) y el materialismo «científico» o filosófico ". (Bueno, 1990. pp 10).

\section{LA UNESCO Y EL SUPUESTO «PATRIMONIO INMATERIAL»}

Recientemente, también la UNESCO, con la intención de divulgar la Convención de 2003, ha contribuido a la confusión, pues ha colocado en su sitio WEB un mensaje en el que pretende homologar los contenidos del denominado «PATRIMONIO INMATERIAL» con el PATRIMONIO VIV0, el primero debajo en mayor formato (el oficial) y el segundo algo menor encima, que se ha ido imponiendo también en el discurso internacional, como si fueran sinónimos.

Un análisis semántico al respecto nos haría posible descalificarlos como sinónimos, ni siquiera como términos concomitantes, aunque lo único que tienen en común es que ambos se refieren a calificativos del patrimonio.

En realidad, nos encontramos con concepciones disyuntivas, pues si supuestamente hubiera un "patrimonio inmaterial», solo desde un punto de vista ingenuo o irracional podría considerarse patrimonio vivo. De hecho, si aceptamos como válido el concepto de patrimonio vivo, este no puede consi-derarse desde un punto de vista racional como equivalente al supuesto «patrimonio inmaterial», pues como bien han demos-trado la biología y todos los campos del conocimiento con ella relacionados, la vida es una forma particular de la materia orgánica con determinado tipo de orden, desde las algas unicelulares hasta las plantas y los animales más complejos, incluidos los seres humanos, generadores, portadores y transmisores del pa- 
trimonio cultural no limitado al campo de los objetos que, como bien señala la Convención, es necesario salvaguardar.

Al mismo tiempo, la aceptación conceptual del patrimonio cultural vivo como sustituto del supuesto «patrimonio cultural inmaterial» no implica necesariamente, como forma de interpretación dogmática, el reconocimiento o identificación de un supuesto «patrimonio cultural muerto», pues eso significa retroceder al error inicial; es decir, a la propia concepción maniquea que generó el pseudoconcepto de «patrimonio cultural inmaterial».

Otra contradicción derivada de lo anterior se presenta a la luz en El mensajero del Patrimonio Inmaterial, un boletín mensual de la UNESCO, que viaja por la Internet en formato PDF, en cuyo fondo aparece en grande: patrimonio vivo. Este boletín publicado en febrero de 2006 pone al día de modo sencillo el estado actual de los países que han ratificado tan importante Convención y otras noticias de interés. Aunque el esfuerzo es muy loable, en su primer Editorial salta a la vista la intención de Rieks Smeets de la «Sección de Patrimonio Inmaterial» de homologar ambos términos:

\footnotetext{
"No podría haber habido mejor ocasión para lanzar El Mensajero del Patrimonio Inmaterial que la inminente entrada en vigor de la Convención del PCI. Pero más allá del momento histórico, esta nueva publicación mensual tiene como principal objetivo informar sobre la miríada de actividades pasadas, presentes y futuras en las que participa la Sección de Patrimonio Inmaterial (ITH) de la UNESCO en todo el mundo.

Concebida para profesionales del PCI y otros interesados, como la UNESCO en general y otras agencias de la $\mathrm{ONU}$, delegaciones nacionales, comisiones nacionales, oenegés, socios en el sector privado y otros actores de la sociedad civil, el Mensajero proporcionará información actualizada sobre la ratificación e implementación de la Convención. Nuestro boletín también informará sobre actividades prácticas y de investiga-ción, ejemplos a seguir, planes de acción de las Obras Maestras, Tesoros Humanos Vivos, lenguas en peligro, tradiciones orales, música tradicional, danza y mucho más. Gracias a la utilización de las rúbricas Agenda y Noticias del Patrimonio Vivo, nuestros lectores podrán mantenerse al corriente de conferencias, conmemoraciones, publicaciones, exposiciones y novedades en la sección ITH, como por ejemplo el relanzamiento de nuestra página Web.

Esperamos que este boletín se convierta en una he-rramienta útil para todos aquellos que contribuyen, directa o indirectamente, a la salvaguarda del patrimonio vivo de la humanidad, y esperamos nos envíen sus comentarios y sugestiones. (UNESCO, 2006).
}

Este intento de homologación entre el supuesto «patrimonio inmaterial» y el patrimonio vivo se repite como hábito del dicurso en los otros boletines ${ }^{8}$. Aunque la falsa homologación es muy criticable, pues se trata de dos términos no compatibles, el criterio sobre el patrimonio cultural vivo se va abriendo paso poco a poco pese a las iniciales manipulaciones erradas.

Por ello, se ha insistido en diversas ocasiones (Guanche, SF) que el concepto de patrimonio cultural vivo no puede ni debe reducirse de modo simplista al concepto de patrimonio vivo, pues el ámbito denominativo de este último es mayor: la vida; mientras que el primero se encuentra circunscrito a lo cultural (la vida humana en sociedad). Como patrimonio vivo solamente, también puede considerarse la valoración humana sobre la biota terrestre y marina de un país, de una región, o del orbe, tanto la endémica como la de un área mayor.

Es precisamente la cualidad cultural la que diferencia este patrimonio vivo y lo específica en su dimensión antrópica.

Por su parte, el criterio denominativo de «patrimonio inmaterial» resulta, desde el punto de vista lógico, independientemente de su originaria acepción jurídica, una entelequia ${ }^{9}$, sinsentido, una falsedad. En este contexto vale preguntarnos: ¿Cómo es posible valorar en la condición de patrimonial algo que no existe en ninguna de las formas de manifestarse la materia?

La imposición jurídica del pseudoconcepto de «patrimonio inmaterial» evidencia una subordinación de los valores patrimoniales relacionados con la sabiduría, las habilidades y otras acciones humanas a los criterios preestablecidos por el derecho internacional, sin una adecuada actualización a los cambios más recientes en el desarrollo del conocimiento.

Cabría también entonces preguntar: ¿Qué es lo inmaterial? ¿Existe acaso determinada forma de la inmateria? ¿Es acaso lo inmaterial algo existente o algo construido idílicamente por la propia ignorancia humana? ¿Es lo inmaterial un acto de insuficiencia gnoseológica para denominar algo que no se ha podido conocer adecuadamente? En cambio, ya se venía hablando desde hace más de una década del patrimonio cultural vivo y se le había hecho poco caso al asunto, así como al significado y actualidad del concepto. Por ello, los pseudoconceptos «patrimonio cultural inmaterial», o su versión simplificada de «patrimonio inmaterial», lejos de basarse en una propuesta racional, son focos de confusión que parten de la extrapolación o el acomodo mecánico de términos jurídicos con base en una filosofía idealista y centrada en el derecho individual, con un evidente sustrato religioso en lo que concierne a la añeja separación del cuerpo y el alma, al ser de la conciencia o del espíritu.

8

Véanse a modo de ejemplos los boletines dedicados a las lenguas en peligro, septiembre de 2006, p.8. y el no. 6, de mayo de 2007, que abre con este título sin comentarios: "Nuestro patrimonio vivo, explorar lo inmaterial" para anunciar una Exposición de fotografías al aire

9

Aunque el concepto de entelequia fue inicialmente definido por Aristóteles como la realzación de toda la perfección que un ser puede alcanzar y luego Gottfried Wilhelm Leibniz dio al concepto un uso diferente relacionado con las mónadas, o entidades individuales aquello que no existe y es una mera abstracción sin fundamento. 
Este campo del conocimiento sobre la diversa complejidad de la materia y la anulación de «lo inmaterial» ya ha sido resuelto en el orden filosófico y los nuevos descubrimientos científicos subrayan la riqueza y amplitud del campo, tanto en los niveles micro como macro de la realidad.

Desde este punto de vista, los pseudoconceptos «patrimonio cultural inmaterial» $\mathrm{y}$ «patrimonio inmaterial» pueden ser equivalentes, por lo absurdo, a la cuadratura del círculo, al kerosene en polvo o a la escuadra redonda; es decir, sofismas ${ }^{10}$ o términos imaginados que solo operan en la mente pero no forman parte de la realidad.

No obstante las confusiones generadas por el mal manejo de términos y conceptos, la Convención de 2003 sigue siendo un importante paso de avance que es necesario apoyar y desarrollar. La idea de motivar las discusiones al respecto debe tomar muy en serio los objetivos de la Convención, que puede y debe ser enmendada y que como toda obra humana puede ser perfectible. Al mismo tiempo, por el respeto que merecen el trabajo de la UNESCO como institución internacional y los múltiples esfuerzos que se realizan a favor de las ideas y del patrimonio mundial. Nadie tiene la última palabra, pero considero necesario compartir ideas que no necesariamente siguen la rima a lo que puede ponerse de moda y repetirse de modo mimético sin mayor reflexión al respecto. El valor de la significación y las acepciones que pueden tener los términos no pierde ni perderá interés, pues por ejemplo, todavía se dice en el lenguaje corriente «planeta» y hace ya más de un milenio se superó la visión ptolomeica del universo. Se sabe que los grandes cuerpos esferoides que giran de diversos modos y tiempos en torno al Sol no son planos y se crean convenciones terminológicas para denominar algo fuera de toda lógica y luego también se dice que la ciencia debe acercarse a la verdad y, de ser posible, ser su fiel defensora.

\section{PATRIMONIO CULTURAL VIVO VS. «PATRIMONIO INMATERIAL»: VENTURAS Y DESVENTURAS}

El flujo y reflujo de ideas y puntos de vista encontrados sobre el empleo por unos y otros de los conceptos de patrimonio cultural vivo, «patrimonio inmaterial» y cultura popular tradicional, a modo de ejemplos, se evidencia en diversos documentos de Iberoamérica, que no siempre se toman en consideración unos a otros y que ponen de relieve una desconexión entre lo que se acuerda en contextos internacionales y lo que luego se hace. Algunos textos ya emitidos al respecto pueden también contribuir a la reflexión crítica sobre el tema.

Desde el 26 de agosto de 1995 se había firmado en Guatemala la Convención Centroamericana para la Protección del Patrimonio Cultural (1995), con la participación de repreual se intenta demostrar o defender una falsedad con la intención de convencer de llo. Suele elaborarse de acuerdo con las reglas de la argumentación lógica, pero siemcionadamente erróneo las reglas de la deducción. Este sofisma («patrimonio cultural inmaterial») se ha basado en confundir el alcance semántico y complejo de la materia sentantes de Costa Rica, El Salvador, Nicaragua, Panamá y el país sede. En su Artículo Séptimo se establece una clara distinción operativa entre: I. Bienes Culturales Inmuebles, II. Bienes Culturales Muebles y III. Patrimonio Cultural Vivo; este último «Representado por personas e instituciones de trayectoria excepcional y trascendencia social, así como por comunidades, cofradías, idiomas y costumbres».

No es casual ni raro que precisamente en Guatemala se haya planteado tal definición, gracias a la amplia experiencia adquirida en los estudios sobre la cultura popular tradicional. Recordemos que el Centro de Estudios Folklóricos de la Universidad de San Carlos de Guatemala es una prestigiosa institución especializada en este campo, creada desde 1967, (USAC) que mucho ha contribuido a conocer, proteger y divulgar esta parte del patrimonio cultural de nuestros pueblos.

En este contexto, un estudio realizado en Colombia (Bolívar Rojas, SF) sobre las «Artesanías y artesanos: lo hecho a mano es útil, bello e inclusive sagrado» parte también de la idea del patrimonio cultural vivo como el patrimonio cultural vigente, y valora que «las artesanías representan uno de los mejores ejemplos que dan rostro y personalidad a un grupo humano. Podría decirse que identifican o dan identidad a una región, y se constituyen en algo así como su carta de presentación ante el mundo, su proyección ante los otros».

Debido a la polivalencia de la creación artesanal, se deduce la importancia que tienen los propios artesanos en su preservación. Para esto resulta necesario considerar simultáneamente que la existencia de la artesanía, su rescate y preservación, su difusión, depende al mismo tiempo de lo que ocurra con los artesanos que las producen. En el ámbito del patrimonio cultural vivo el ser humano y su saber es lo prioritario, y atender a la conservación de su experiencia y al mejoramiento de sus condiciones de trabajo debe ser el principal objetivo de toda labor de defensa y promoción de esta modalidad del patrimonio cultural. Por ello señala que

\begin{abstract}
"Hay dos maneras de aproximarse a ello: desde los objetos, considerando sus propiedades formales, estéticas y simbólicas, su función y los materiales de que están elaborados. En este sentido puede hablarse de un enfoque de la artesanía en cuanto patrimonio artístico del pueblo, es decir, bajo el rubro de las artes populares. Pero también puede abordarse desde sus portadores y artífices: los artesanos. En este caso el interés se centra en las condiciones sociales y tecnológicas de su trabajo, la gama de los oficios y técnicas empleadas, la transmisión del saber, las características del taller o unidad de producción artesanal. En otros términos, un enfoque social del patrimonio vivo. "
\end{abstract}

El 8 y 9 de noviembre de 2001 se efectuó en Lima (Perú) la V Conferencia Iberoamericana de Cultura, cuyos acuerdos se dan 
a conocer como Declaración de Lima. En ella se señala que los ministros de Cultura y responsables de Políticas Culturales de Iberoamérica reconocen que durante la última década nuestros países han consolidado un espacio cultural común, fundado en nuestra diversidad cultural, orientado a mejorar la calidad de vida de nuestros pueblos, pero no se hace referencia al denominado «patrimonio cultural inmaterial», sino al patrimonio cultural vivo. En este sentido la Declaración señala:

La existencia de patrones comunes para entender variados aspectos de la cultura distingue a Iberoamérica de otras regiones del mundo. Tal es el caso de la distinta percepción en torno al patrimonio cultural en general, con especial énfasis en la creatividad, el patrimonio vivo de nuestros países, los derechos a la propiedad intelectual o las relaciones entre economía y cultura. Debemos profundizar más éstas y otras cuestiones para una mejor inserción del espacio iberoamericano en los procesos globales.

Más adelante, tras señalar un amplio conjunto de organizaciones gubernamentales, no gubernamentales e internacionales presentes en el encuentro, el primero de los lineamientos para la cooperación cultural Iberoamericana hace énfasis en "fortalecer los programas existentes, con especial énfasis en el patrimonio cultural vivo y las industrias culturales". Sin embargo, lo formulado no siempre coincide con los conceptos que luego se reformulan en otros contextos.

Es muy significativo también que desde la década de los noventa del siglo XX la mayoría de las legislaciones autonómicas de España dedicadas a este tema se refieren a la cultura popular y tradicional, bien como parte del patrimonio etnográfico, bien en forma de leyes propias, pero tampoco cayeron en ese momento en la trampa del supuesto «patrimonio inmaterial». ${ }^{11}$

En diversos eventos internacionales tampoco los estudiosos del tema han permanecido callados ni pasivos ante tal situación. Durante la 20 ${ }^{\text {a }}$ Conferencia General del Consejo Internacional de Museos, efectuada en Seúl, Corea del Sur (2004), el director del Centro de Tradiciones Populares y Patrimonio Cultural del Instituto Smithsonian, de Estados Unidos de América y miembro del jurado internacional sobre «Obras Maestras del Patrimonio Oral e Inmaterial de la Humanidad» de la UNESCO, Richard Kurin (2004), planteó que la referida «Convención fomenta la supervivencia y la vitalidad del patrimonio cultural vivo $^{12}$ a escala local, regional y nacional en todo el mundo frente a la creciente globalización». También resaltó (Kurin, 2004, p. 7) que «La definición de patrimonio cubre, en líneas uña, entre otros.

generales, las prácticas sociales, las tradiciones estéticas y los modos de conocimiento perpetuados en el seno de una comunidad cultural», lo que de hecho opera de modo interactivo con las evidencias objetuales del patrimonio. Considera Kurin (2004, p. 7) la diversidad de ámbitos disciplinares que contempla la Convención, como «etnografía, arte, historia, ciencias y tecnología» junto con los métodos de salvaguardia.

Otra posición contestataria fue la de Kenneth Hamma ${ }^{13}$, con un texto denominado ¿Inmaterial yo? (Karp, 2004, p. 23) lo que puso el dedo en la yaga de las disquisiciones absurdas sobre la supuesta «inmaterialidad» del patrimonio cultural. Este autor valoró la importancia del patrimonio digital y consideró diversas medidas de protección seguras que deben trascender el ciclo vital de sus creadores o autores.

En el área andina, por ejemplo, ha sido publicado un sitio Web sobre el Patrimonio vivo que incluye a Bolivia, Colombia, Ecuador, Perú y Venezuela (www.patrimoniovivo.org) con diversos tópicos de interés como sus tesoros humanos vivos, vitrina virtual de artesanías, legislación y directrices, lo que no solo hace posible conocer el estado de cada uno de los países sino especialmente comparar métodos y experiencias de trabajo al respecto.

A diferencia de lo anterior, en Brasil, el Instituto del Patrimonio Histórico y Artístico Nacional (IPHAN), adscrito al Ministerio de Cultura, tiene encomendadas actividades de investigación, la identificación y catalogación de bienes y recursos del patrimonio histórico y cultural, así como la supervisión de las obras de conservación y los programas de enseñanza y sensibilización del público. Desde que se puso de manifiesto la necesidad de proteger de alguna manera lo que ellos denominaron como «Patrimonio Cultural Inmaterial», se creó en el año 2000 un registro de activos culturales inmateriales, que se caracterizó por ser un instrumento para el reconocimiento y una mayor valoración del patrimonio inmaterial. Esta experiencia influyó en la propia creación de la Convención y en el posterior Registro del Patrimonio Inmaterial y su Expediente. (UNESCO, 2005).

Más recientemente, a partir de un Acuerdo entre la UNESCO y el gobierno del Perú, el 22 de febrero de 2006 se creó el Centro Regional para la Salvaguardia del Patrimonio Cultural Inmaterial de América Latina (CRESPIAL), con sede en la ciudad del Cusco. Este Acuerdo toma en consideración la Declaración final de la Cumbre Iberoamericana de Jefes de Estado y de Gobierno, celebrada en Santa Cruz de la Sierra (Bolivia) en noviembre de 2003, la Resolución 33 C/40 de la Conferencia General de la UNESCO que tiene por objeto propiciar la cooperación internacional en materia de salvaguardia del patrimonio cultural inmaterial, y que la Conferencia General ha autorizado al director general (Resolución 33 /C 46) a firmar con el Gobierno del Perú un acuerdo conforme al proyecto sometido a la Conferencia General. 
ARTE \& DISEÑO, ISSN: 1692-8555, Vol. 12 Núm. 1, Enero - Junio 2014 JESÚS GUANCHE PÉREZ

El Acuerdo señala que «Los Estados Miembros de la región de América Latina que deseen participar en las actividades del Centro, [...] deberán enviar al Director General de una notificación en este sentido y designar el organismo nacional encargado de la salvaguardia del patrimonio cultural inmaterial».

Sin embargo, la crítica periodística (Otoya, 2007) reconoce que: «El Patrimonio Cultural Inmaterial (PCI) de Latinoamérica, producto del conocimiento tradicional y la creación artística de antiguas civilizaciones, es víctima de la piratería y el robo, pero también del olvido de sus herederos y la ignorancia de los Estados».

Así lo afirmó en una entrevista el antropólogo Jaime Urru-, tia director del CRESPIAL, al referir que la labor de este organismo - integrado por Argentina, Bolivia, Brasil, Colombia, Chile, Ecuador y Perú- aún «está en la bruma del conocimiento». Reconoció que en Latinoamérica este legado «no está protegido de la misma manera como lo está el patrimonio material», en relación con los marcos legales para su salvaguardia. Puso de ejemplo «el conocimiento y uso de hierbas y plantas medicinales de indígenas de toda Latinoamérica», como la ayahuasca o el huacatay, que están «en peligro de ser patentados» sin que se reconozcan sus orígenes.

También criticó a las naciones «que no han suscrito convenios internacionales que protegen el conocimiento de pueblos originarios». Reconoce que Brasil «es el más avanzado» en cuanto a la protección de su legado «inmaterial», refiere la declaración de Patrimonio Cultural al oficio de las olleras de Goiabeiras, la pintura corporal y gráfica de los indios wajapi, la Samba de Roda, la celebración religiosa de Belém del Pará, la técnica para hacer Viola de Cocho y el Oficio de Baiana de Acarajé. Valora que «en Colombia hay instituciones fuertes y una serie de programas destinados a recopilar y difundir el legado cultural», como la creación de un registro denominado Bitácora del Patrimonio. Destaca los esfuerzos de Argentina en la recopilación de testimonios orales desde hace más de una década y cuenta con un proyecto para salvaguardar el patrimonio alimentario. En Chile hay iniciativas para proteger estos bienes, entre ellos los espectáculos circenses populares, lenguas indígenas, conocimientos relacionados con la visión del universo y técnicas artesanales. En Ecuador, la Carta Magna de este país incorpora en sus artículos la protección del «patrimonio cultural inmaterial», pero falta emitir una ley al respecto. En Perú y Bolivia, los gobiernos e instituciones cuentan con menos recursos para la protección de sus «bienes inmateriales», aunque la transmisión de los conocimientos tradicionales aún es dinámica gracias a los actores sociales. Recuerda que la conservación y catalogación del «Patrimonio Inmaterial» fue planteada por Bolivia en 1973, y desde entonces se han llevado a cabo múltiples reflexiones y reuniones que han culminado con la creación del CRESPIAL. En esta misma dirección, la Convocatoria del Convenio Andrés Bello (2006) contribuye a la referida confusión con la intensión de salvaguardar lo que ellos mismos denominan Patrimonio cultural vivo:
En los últimos años el CAB ha liderado la valoración, preservación y divulgación del patrimonio cultural vivo de los países que hacen parte del Convenio. Esta iniciativa ha estado motivada por la convicción de que el patrimonio cultural de nuestros pueblos no sólo está compuesto por las creaciones materiales representadas en los monumentos históricos y los documentos escritos que nos ha legado el pasado. Si bien este acervo es de gran importancia también urge incluir en el concepto de patrimonio cultural todas aquellas creaciones inmateriales a las cuales las mismas comunidades asignan un valor fundamental. Entre ellas se destacan las expresiones de la vida cotidiana y espiritual, cuyas manifestaciones están en profunda relación con el fortalecimiento de la identidad, el sentido de pertenencia y las proyecciones de futuro que cada pueblo, nación o comunidad sueña.

La confusión, ya oficializada, se asume como verdad, se repite, se generaliza y se difunde por Internet, como el caso del sitio sobre Patrimonio inmaterial colombiano ${ }^{14}$, donde señalan:

\section{¿PARA QUÉ SIRVE EL PATRIMONIO CULTURAL INMATERIAL?}

El patrimonio sirve para llevar la vida sin perder nuestra originalidad, nuestra forma particular de ser.

El patrimonio cultural inmaterial nos ayuda a entender quiénes somos y a reflexionar sobre cómo queremos ser; fortalece a nuestros grupos y nos permite recordar la historia y adaptar la cultura a los nuevos tiempos, a la vez, nos permite tener un desarrollo propio y no impuesto ni copiado. Le da significado a lo que hacemos y nos distingue de otros al tiempo que intercambiamos saberes con ellos.

El patrimonio cultural inmaterial nos hace parte de un grupo y nos arraiga a nuestro territorio. Posibilita la comunicación para recibir y transmitir conocimientos. Nuestro patrimonio cultural inmaterial es el conocimiento acumulado por muchas generaciones que se han adaptado al entorno, para dar solución a sus necesidades y anhelos. Podemos renovar el patrimonio cultural inmaterial, porque es un patrimonio vivo ${ }^{15}$; seguirá siendo eso, un patrimonio, en la medida en que lo heredemos a las siguientes generaciones.

En un estudio sobre La gestión del patrimonio cultural inmaterial en Venezuela se identifica el Patrimonio vivo como: 
ARTE \& DISEÑO, ISSN: 1692-8555, Vol. 12 N 1, Enero - Junio 2014 El imaginado «patrimonio inmaterial» ¿un acercamiento a la verdad o una falsedad engañosa?, págs. 62 - 71

“...los idiomas y sus variantes, representaciones, creencias, saberes y prácticas de carácter artístico, artesanal, recreativo, técnico, mágico, religiosas, literarias, gastronómicas, y las expresiones, obras y expresiones del ingenio creador cuya manifestación sea inseparable de determinados comportamientos individuales o colectivos de excepcional trascendencia para la valoración y conocimiento de la historia e identidad cultural." (Morales, 2005, p. 12).

Esta importante definición de contenido explicativo, incluso más abarcadora que la que aparece en la Convención Centroamericana para la Protección del Patrimonio Cultural, se subsume en un supuesto "patrimonio cultural inmaterial» abarcador y programático que ha contado con importantes antecedentes, investigaciones y publicaciones realizadas por el Instituto Nacional de Cultura y Bellas Artes (INCIBA), luego, Consejo Nacional de la Cultura (CONAC) y su Dirección de Patrimonio Cultural, las instituciones adscritas en ese momento, como el Centro de las Culturas Populares y Tradicionales (CCPYT), y el Museo del Folklore, posteriormente Fundación de Etnomusicología y Folklore (FUNDEF) y actualmente el Centro de la Diversidad Cultural como fundamento del trabajo patrimonial en Venezuela.

Sin embargo, lo señalado anteriormente desconoce o no se toma en consideración la legislación de las autonomías de España, la Convención Centroamericana para la Protección del Patrimonio Cultural de 1995, y el texto de la Declaración de Lima, de 2001, anteriormente referidas, lo que evidencia la desconexión entre los países en relación con el patrimonio cultural y con la intención de acuerdos de alcance Iberoamericano.

Estas reflexiones se proponen contribuir a la discusión sobre tan controvertido tema. Sabemos que mucho se ha avanzado, especialmente en las más recientes convenciones de la UNESCO. Tanto la Convención para la Salvaguardia del Patrimonio Cultural Inmaterial (2003), como la Convención sobre la Protección y Promoción de la Diversidad de las Expresiones Culturales (2005) han sido pasos muy significativos al colocar la idea antropológica de cultura como parte esencial de la condición humana. Se ha superado la limitada concepción dieciochesca (iluminista) que la reducía a los saberes artístico-literarios.

Pero algún día, no muy tarde, también los pueblos dirán, como señaló Kenneth Hamma en Corea del Sur durante la $20^{\text {a }}$ Confeencia General del Consejo Internacional de Museos: ¿INMATERIAL YO? Y se pondrán en orden las ideas y las acciones.

\section{REFERENCIAS BIBLIOGRÁFICAS}

Bolívar Rojas, Édgar. La artesanía: patrimonio vivo de nuestras culturas, disponible en http://museo.udea.edu.co/codice/ codice7/patrimonio2.html

CONVENCIÓN CENTROAMERICANA PARA LA PROTECCIÓN DEL PATRIMONIO CULTURAL, Guatemala, 1995.

CONVOCATORIA AL VI PREMIO CAB SOMOS PATRIMONIO, de 2006, versión en formato PDF (español).

V Conferencia Iberoamericana de Cultura (2001) Declaración de Lima, Lima, 8 y 9 de noviembre de 2001.

Getmanova, A. et al. (1991). Lógica: en forma simple sobre lo complejo. Diccionario, Moscú.

Guanche, Jesús. El patrimonio cultural vivo y su protección, en www.uney.edu.ve/publicaciones/patrimonio-vivo-guanche.pdf

Gustavo Bueno (1990). Materia, Pentalfa, Oviedo.

Microsoft Encarta, (2007). Microsoft Corporation.

Morales M., Patricia (2005). La gestión del patrimonio cultural inmaterial en Venezuela, Caracas (Venezuela).

Otoya, Rocío. El Patrimonio Cultural Inmaterial latinoamericano sigue en el olvido, disponible en

http://www.lostiempos.com/noticias/31-05-07/31_05_07_ultimas_vyf3.php

Patrimonio cultural colombiano, disponible en http://www.mincultura.gov.co/patrimonio/patrimonioInmaterial/secciones/ que_es/para_que_sirve.htm

Patrimonio vivo, disponible en http://www.patrimoniovivo.org/ content/view/91/100/1/4/

Smeets, Rieks (2006). El mensajero del Patrimonio Inmaterial, $\mathrm{n}^{\circ} 1$, febrero de 2006, en SECCIÓN DE PATRIMONIO INMATERIAL (ITH) www.unesco.org/culture/ich

Zugasti, Eduardo Robredo (2002). ¿Qué es la «materia»?, disponible en http://www.nodulo.org/ec/2002/n007p01.htm

\section{FORMA DE CITAR ESTE ARTÍCULO}

Guanche Pérez, J. (2014). El imaginado «patrimonio inmaterial» ¿un acercamiento a la verdad o una falsedad engañosa? Revista Arte y Diseño Facultad de Arquitectura, Arte y Diseño, Universidad Autónoma del Caribe, Barranquilla. ISSN 1692- 8555 Vol. 12 (N.1). P.P $62-71$ 